\title{
Attitude and education needs of emergency doctors in providing palliative and end-of-life care in Hong Kong: A prospective cross-sectional analysis based on self-reported surveys
}

\section{Kwun Hang Wong}

North Lantau Hospital

Marc Li Chuan Yang ( $\square$ marcyang@gmail.com )

Chinese University of Hong Kong Faculty of Medicine https://orcid.org/0000-0002-0829-5339

Raymond Kam Wing Woo

Caritas Medical Centre

Oi Fung Wong

North Lantau Hospital

Wing Yan Kwong

Queen Elizabeth Hospital

Choi Fung Tse

Tin Shui Wai Hospital

Shing Kit Lam

Poh Oi Hospital

Hin Man Ma

North Lantau Hospital

Chau Hung Albert Lit

North Lantau Hospital

\section{Yau Ngai Shih}

Princess Margaret Hospital

Research article

Keywords: Pain, dying, symptom management, critical care

Posted Date: June 17th, 2020

DOI: https://doi.org/10.21203/rs.3.rs-34967/v1

License: (c) (1) This work is licensed under a Creative Commons Attribution 4.0 International License.

Read Full License 
Page $2 / 21$ 


\section{Abstract}

Background: With the aging population in Hong Kong, the importance and need of palliative care and end-of-life (EOL) care are brought into the spotlight. The Accident and Emergency Department (AED) is often the first medical contact for the public. The objectives of this study were to evaluate the attitude of emergency doctors in providing palliative and EOL cares in Hong Kong, and to investigate the education needs for emergency doctors in these areas.

Methods: A questionnaire study was conducted involving emergency doctors from 6 AEDs in Hong Kong. The questionnaires covered the attitudes of emergency doctors towards the palliative and EOL cares in terms of the role of palliative and EOL care in AED, the specific obstacles in providing such cares, their comfort level with the cares and further education needs The attitudes of emergency doctors from the AEDs with EOL care service were compared with those from the AEDs without such services.

Results: One hundred and forty-five emergency doctors completed the questionnaires, in which 60 respondents from the AEDs with EOL care service. Significant proportions from both groups recognized that palliative and EOL cares were an important competence for them, but its role and priority in emergency care were uncertain. Lack of time and access to palliative care specialists/ teams were the major barriers. Participants from AEDs with EOL care service were more comfortable to provide the care and discuss it with patients and relatives. Further education needs identified including management of physical complaints, communication skills and EOL care ethics.

Conclusions: The study identified obstacles in promoting palliative and EOL cares in the AEDs in Hong Kong. Education on the communication skills and ethical issues were necessary as well. With the combination of elements of routine AED practice and the basic palliative medicine skill set, it would promote the development of this emerging field in Emergency Medicine in the future.

\section{Background}

The aging population imposes significant burden on different aspects in the society worldwide, particularly the demands in the health care service. Hong Kong is also facing the same problem. The proportion of elderly people aged 65 and above is expected to increase from 16\% in 2016 to $31 \%$ in 2046 . In 2014, there were approximately 46000 deaths in Hong Kong (1), in which about $80 \%$ were elderly people aged 65 or above. Care for elderly patients with multiple comorbidities and patients with terminal incurable diseases focus on improving the quality of life, i.e. palliative and end-of-life (EOL) care, instead of aggressive disease-directed treatments.

Palliative medicine is defined by the World Health Organization (WHO) as "an approach that improves the quality of life of patients and their families facing the problem associated with life-threatening illness and terminal disease, through the prevention and relief of suffering by means of early identification and impeccable assessment and treatment of pain and other problems, physical, psychosocial and spiritual problems" (2). 
EOL care, as one of the important elements in palliative care, encompasses the provision of care to the imminently dying patients. According to the General Medical Council of the United Kingdom (3), patients were 'approaching the end of life' when they were likely to die within the next 12 months. This includes patients whose death was imminent (expected within a few hours or days) and also those with:

1. advanced, progressive, incurable conditions

2. general frailty and co-existing conditions that meant they were expected to die within 12 months

3. existing conditions if they were at risk of dying from a sudden acute crisis in their condition

4. life-threatening acute conditions caused by sudden catastrophic events.

The use of healthcare service rises in the last 6 months, especially in the last 2 months, of life. The average number of AED attendances and hospitalization days of elderly patients in their last year of life are 5 and 10 times of other elderly patients respectively (4). Therefore, with the combination of an aging population and increased burden from chronic diseases, emergency doctors are expected to play a more important role in the care of this group of patients, not limiting to acute emergency care but also a good EOL care.

Emergency physicians have been traditionally tasked with many roles $(5,6)$. With the above mentioned changes in the population characteristics, emergency physicians have already started to promote EOL care in their practise. For example, the American Board of Emergency Medicine has established a subspecialty of hospice and palliative medicine in 2006 (7). Research on implementing palliative and EOL care in AEDs has been conducted in different countries. Most of the research subjects were emergency nurses (8-11) and only a few studies focused on emergency doctors (12-14). EOL care was a potential field of development in the EM specialty in Hong Kong. However, research on the perceptions from the local emergency doctors on the provision of EOL care in the AED was still lacking.

\section{Objectives}

The objectives of this study were to evaluate the attitude of Hong Kong emergency doctors in providing palliative and EOL care, and to investigate the education needs for emergency doctors in palliative and EOL care.

\section{Methods}

\section{Study Design}

This was a multicentre cross-sectional questionnaire study. We collected data on the emergency doctors' attitude and perceived education needs using a self-administered survey. The findings in emergency doctors from the AEDs with EOL care service were compared with those from the AEDs without such services. The reporting of this study complies with the The Strengthening the Reporting of Observational 
Studies in Epidemiology (STROBE) Statement: guidelines for reporting observational studies (15) with modification suggested by the review of Bennet et al (16).

\section{Setting}

The participants were recruited from six AEDs in Hong Kong. Among them, North Lantau Hospital and Queen Elizabeth Hospital were providing AED based EOL service (see table 1). In QEH AED, the EOL service was provided by a dedicated team of emergency physicians with a dedicated inpatient bed inside the EMW $(11,17)$ Consultations from other inpatient departments were assessed by the on-duty emergency physicians and suitable patients would be taken over to the EMW for management. Some patients would also be admitted to the EOL service directly from the resuscitation bays. In NLTH, terminally-ill patients requiring EOL care were identified by the AED team and directly admitted to the EMW for management. Critically ill patients with futility of life-sustaining treatment were also included in the EOL program after consensus of withholding and withdrawing life-sustaining treatment was made among the care team, the patients and their families (6). There was no EOL service in the AEDs of the other four hospitals yet.

\section{Participants}

The target population was the emergency doctors working in the six participating AEDs. Doctors who were not working regularly in the AED, e.g. trainees rotated from other specialties or part-time staff were excluded.

\section{Variables}

Baseline variables of each participant were collected as part of the questionnaire. Basic trainees in emergency medicine were defined as specialist trainees who had not passed the intermediate examination of the Hong Kong College of Emergency Medicine. They typically had less than three years of experience. Higher trainees were defined as trainees who have passed the intermediate examination but not the final exit examination of the College, they typically have less than six years of training. Items and variables in the questionnaire are discussed separately.

\section{Data sources/ measurement}

\section{Description of the research tool}

The contents of the questionnaire were derived from a validated questionnaire (18), an overseas palliative and EOL care study (19) and local expert opinions. Permissions for using the context of the questionnaire and the overseas study had been obtained from the authors. For the content of the questionnaire, apart from the baseline characteristics of the participants (Part A, question 1-9), 2 main dimensions were assessed in the survey including their attitude in providing palliative and EOL care (Part B, question 10-24 (15 statements)), and their education needs (Part C, questions 25-35 (11 items). The participants were asked about their overall attitude in providing palliative and EOL care in their AED. The statements in Part 
B were divided into 4 domains, including the role of palliative and EOL care (statements 1-3,6,7), specific obstacles (statements 4,8,9,11-14), the comfort level with palliative and EOL care (statements 5 and 10) and overall impression towards palliative and EOL care (statement 15).

\section{Instrument reliability and validity}

The content validity of the questionnaire was done by Rivera et al (19). We sought opinion from a panel of experts, including three experienced emergency physicians and a palliative medicine specialist, for grammar, syntax, organization and appropriateness. The questionnaire was then modified according to their comments.

\section{Scoring Method}

There were 5 Likert scale options for each question in Part B and Part C of the questionnaire, which included strongly agree, agree, neutral, disagree and strongly disagree. Besides, the participants were invited to indicate on which topics they would like to have further education on palliative and EOL care.

\section{Method of questionnaire administration}

Hard copies of the questionnaire were distributed by the investigators through direct personal invitation. For the data privacy, no personal identifying data was collected so as to maintain anonymity and the data access was restricted to the investigators only.

\section{Bias}

Since the original questionnaire was not validated in the Chinese populations we mitigated this by modifying the questionnaire with expert input described above.

\section{Study Size}

All the AED medical staff of the six hospitals were included for recruitment and determined the sample size.

\section{Method of sample selection}

Target participants were identified according to the most updated staff list from the corresponding departments.

\section{Quantitative Variables}

Staff experience was separated into groups of 5 years intervals. This was done arbitrarily. No other quantitative data needed modification or grouping.

\section{Statistical methods}


The Statistical Package for Social Sciences (SPSS) version 20.0 for Windows was used for analysis. Variables were assessed for normality with the Shapiro-Wilk test. Mean/median and frequencies were used to describe data. Scores were assigned for the 5 Likert scale options of each question ( $5=$ strongly agree while $1=$ strongly disagree) and mean/median scores of each question were calculated to reflect the level of agreement for each item. In those items related to the participants' attitude in providing EOL care, the correlations between the level of their attitude in the individual items and their overall attitude in providing EOL care in the AED were calculated using Spearmen's correlations coefficient.

\section{Results}

\section{Participants}

Total 145 returned questionnaires out of total staff of 195 in the 6 AEDs (response rate 74.3\%). Sixty were from the AEDs with EOL service (EOL group) and 85 were from the AEDs without EOL service (non-EOL group). Both EOL and non-EOL group had similar response rates (77.9\% vs $72.0 \%$ ).

\section{Descriptive data}

Details were shown in table 2. One hundred male doctors and 45 female doctors were recruited, with similar ratios in both groups (male: female, 2.21:1 in EOL group, 2.27:1 in non-EOL group). Emergency doctors with experience equal or less than 5 years constitute the main part of the respondents $(30 \% \mathrm{vs}$ $37.6 \%$ ). Distribution of training status of specialty of Emergency Medicine was similar (non-specialist: specialist ratio: 1.31: 1 vs 1.36: 1). In the EOL group, more emergency doctors received on job training about palliative and EOL care compared to non-EOL group (48.3\% vs 31.8\%), although a significant number of emergency doctors in the EOL group still did not receive any training. (46.7\%, Non-EOL: $67.1 \%)$. Besides, despite the difference in the availability of training, self-ratings for knowledge of palliative and EOL care were similar in both groups (no knowledge: $25 \%$ vs $22.4 \%$; general knowledge: $71.7 \%$ vs $77.6 \%$ ). Apart from the availability of palliative and EOL care training (p-value 0.032 ), there were no statistically significant differences in 1) years of AED experience, 2) AED training status and 3) self-rating for knowledge of palliative and EOL care. (corresponding p-values: $0.342,0.841,0.212$ ).

In the EOL group, a larger proportion of emergency doctors felt confident at least most of the time when looking after those who were dying, compared to that in Non-EOL group, though the difference was not statistically significant $(19,31.7 \%$ vs $11,12.9 \%$, p-value 0.107$)$.

\section{Outcome data}

\section{Attitude in providing EOL care}

Results were illustrated in table 3. For the role of palliative and EOL care (statements 1-3,6,7), emergency doctors in the EOL group were more likely to agree with the affirmative statements (questions 1 and 2) and disagree with the opposing statements (questions 3,6,7; P-values of all these 5 statements were less than 0.05 , which were statistically significant. For affirmative statements, statement 1 ("Palliative and 
EOL care is an important competence for an emergency medicine physician.") had the highest score in the EOL group (3.62, SD 0.922). For the non-EOL group, only statement 2 ("I have a clear idea of the role of palliative and EOL care in the emergency department.") showed significant deviation from neutral (i.e. score 3 ), and its score tended to be against the clarity of the role of palliative and EOL care in AED.

For the specific obstacles (statements 4,8,9,11-14), statement 14 had the highest score (3.62, SD 1.010) while statement 4 had the lowest score $(1.95$, SD 0.910), i.e. more emergency doctors in the EOL group thought they did not have enough time during their shifts to provide palliative and EOL care; while they confirmed the presence of palliative and EOL care in their AED. In the non-EOL group, question 8 had the highest scores (3.91, SD 0.718), followed by question 14, while question 11 scored the lowest point (2.78, SD 0.931). It indicated that the lack of access to palliative and EOL care specialists/ teams in the emergency department was the most salient concern, while the identification of patients in need of palliative and EOL care was not difficult for the emergency doctors in the non-EOL group. Most of the statements had the p-values less than 0.05 , except statements 9 and $14(0.104,0.296$ respectively).

For the comfort level with palliative and EOL care (statements 5 and 10), the emergency doctors in the EOL group felt more comfortable in providing palliative and EOL care and less difficult in discussing palliative and EOL issues with patients and/ or their relatives, in which the difference in the mean scores of 2 groups was statistically significant ( $p$-values of both statements were less than 0.05 ).

For overall impression, i.e. statement 15 , the score of the emergency doctors in the EOL group was close to $3(2.93$, SD 1.056) while Non-EOL group's score was 3.55 (SD 0.906). P-value was 0.001 , which was statistically significant. It would indicate that the emergency doctors in the EOL group was slightly more eager to initiate palliative and EOL services in their AEDs.

\section{Correlation between specific obstacles and overall impression}

In order to evaluate the impacts of specific obstacles on the development of palliative and EOL care in AED, Spearman's rank correlation coefficients ( $r$ ) were calculated for each obstacle. From table 4, we could appreciate that all r's had the same sign i.e. positive, which meant the preset opposing statements very unlikely scored high marks while the mark of overall impression was low in the same questionnaire sample. The value of $r$ was the highest for statement $13(0.334)$ while that of statement 12 was the lowest $(0.043)$. It showed that the medicolegal issue would likely discourage the implementation of palliative and EOL care in AED while lack of training in palliative and EOL care did not have significant negative effects. However, in general all r's were less than 0.5 , which meant these obstacles only have weak associations with the overall impression. Most of the $p$-values were less than 0.05 , except question 9 and 12.

\section{Further education needs}

The results were demonstrated in table 5 . From all respondents, most of them wanted to learn more about the pain assessment and management in palliative and EOL care $(n=100,69.0 \%)$, while less 
colleagues were interested to the management of spirituality and cultural aspects ( $n=45,31.0 \%)$. In the EOL group, the education of communication skills was seemed to be the most necessary $(n=42,70 \%)$, while non-EOL group colleagues were more concerned about the pain assessment and management $(n=60,70.6 \%)$. In contrast, the education need for last office and ritual arrangement was less emphasized in EOL group ( $n=24,40 \%$ ), while the emergency doctors in the non-EOL group were less interested in the management of spirituality and cultural aspects $(n=16,18.8 \%)$.

For between-group comparison, only 4 of 11 statements had p-values less than 0.05 (the management of death rattle, feeding in EOL care, psycho-social aspects of EOL care and spirituality and cultural aspects in EOL). There were significant proportion of the emergency doctors in the non-EOL group (above $60 \%$ without "tick" in the box) did not indicate that they needed further educations on these aspects, while about half of those in the EOL group expressed their needs on these topics ( $48.3 \%$ to $58.3 \%$ with "tick" in the box).

\section{Main Results}

Significant proportions from both groups recognized palliative and EOL care was an important competence for them, but was uncertain about its role and priority in AED. Lack of time and access to palliative and EOL care specialists/ teams were the major barriers. Emergency doctors working in the AEDs with EOL service were more comfortable to provide the care and discuss it with patients and relatives. Further education needs, apart from the management of physical complaints like pain management, topics including communication skills and EOL care ethics were also emphasized.

\section{Discussions}

\section{Key Results}

This study was the first study in our Emergency Medicine specialty focusing on the attitude of emergency physicians towards palliative and EOL care in Hong Kong.

From table 2, the baseline characteristics were similar between two groups, except the training in palliative and EOL care (question 4). Although the study design did not include matching, based on the abovementioned similarities, we could be more confident to conclude the associations between the attitudes and/or education needs with the availability of palliative and EOL care in AED.

As one of the international cities with the densest population, our public hospitals are always crowded with patients. Therefore, the time limit in each shift would be the major barrier to providing palliative and EOL care in AED, and it was shown in our study (table 3). However, the correlation to overall impression was relatively weak $(r=0.213, p=0.010)$. On the other hand, the mean scores of Part B statement 7 ("Palliative and EOL care should have a lower priority in the busy emergency department.") were close to neutral with the greatest value of SD. EOL group had a lower mean score, i.e. tended to oppose the lower priority. It was reasonable that the busy working environment would discourage our colleagues to practice 
palliative and EOL care in AED, which were also suggested in other overseas studies $(20,21)$. However, there was still a significant proportion of staff who would like to practice palliative and EOL care in AED. Combining the results of these two statements, we could predict that if resources for palliative and EOL care were available, emergency doctors would be more willing to provide the care.

Part B statement 8 also had very high mean scores among the questions about specific obstacles, in which it was the highest for the Non-EOL group, and at the same time, its SD was the smallest (mean= $3.91, S D=0.718$ ). It showed that the access to palliative and EOL care specialists or teams would greatly affect the desire of the emergency doctors to provide the care in the AEDs, and this desire was seemed to be stronger in the non-EOL group. Providing round-the-clock backup by the palliative physicians would lessen the barrier for palliative care in $\operatorname{AED}(22,23)$. It may be possible to establish a palliative care liaison service modeled after the psychiatric liaison service to better support the emergency physicians.

Medicolegal issues have caused fear for every medical personnel. It was predictable that palliative and EOL care; as a new aspect in AED service, would induce stress to the emergency physicians. Fortunately, despite that the statement 14 had the greatest value of correlation coefficients with the overall impression, the correlation was not strong. Besides, its mean scores were close to neutral for both groups, with smaller value for the EOL group. The statistically significant difference could be related to the availability of established protocols and clinical experience for palliative and EOL care.

Emergency physicians were used to manage various types of pain-related complaints. Even so, significant proportions in both groups (EOL $66.7 \%$, non-EOL $70.6 \%$, overall $69.0 \%$ ) still would like to seek for further education about pain assessment and management. Similarly, one of the distinct themes related to palliative care was inadequate training in pain management(24).

Discussion with patients and their relatives about the palliative and EOL care was not an easy task, let alone during the first medical contact. Within a short period of time, Emergency physicians were expected to formulate a plan of care and inform patients and relatives about the prognosis, goal of care and the dying process in an organized manner within a short period of time. Marck et al. (12) demonstrated several difficulties for the Emergency staff when they were dealing with the patients and relatives during providing palliative and EOL care in AED for cancer patients. The difficulties included difference in expectations (prognosis, usefulness of further investigations and treatments), challenges for staffs (fear of liability or legal issues or criticism) and challenges related to systemic issues (limited information about the patients, limited time for assessment, lack of family presence and/or private room, perception of AED's role as providers of active treatments). Therefore, further education about communication skills and EOL care ethics gained much attention in our study (refer to table 5).

\section{Limitations}

There were several limitations for our analysis in addition to the usual limitation associated by survey studies (e.g. sampling bias, demand characteristic bias, desirability bias and non-response bias). First, not all AED in Hong Kong were included in the stuy. There were 534 Emergency physicians working in the 
AED in public hospitals. Therefore, in this study we only sampled around $27 \%$ physicians working in public hospitals. Second, the response rate for this study $(74.3 \%)$ was quite satisfactory, compared with the usual response rate in surveys in the medical field (25-27). However, the remaining portion of nonrespondents may systematically differ in their responses, the effect on this analysis is unknown.

\section{Conclusion}

To the best of our knowledge, this study was the first study in Hong Kong about the attitude of Emergency physicians towards palliative and EOL care in AED. The results showed several obstacles during the implementation of palliative and EOL care in AED. Further education, especially communication skills and ethical issues, were necessary. Territory-wide study would be useful to further clarify the issue and contribute to the development in this previously overlooked area in our profession. With the combination of elements of routine AED practice and the basic palliative medicine skill set, it would promote the development of Emergency Medicine in the future (28).

\section{Generalisability}

Our current study is applicable to any urban emergency department planning to establish an EoL service.

\section{Abbreviations}

$\mathrm{AED}=$ Accident and Emergency Department.

$\mathrm{EM}=$ Emergency Medicine

EMW= Emergency Medicine Ward

$E O L=$ End-of-Life

NLTH=North Lantau Hospital

QEH= Queen Elizabeth Hospital

\section{Declarations}

\section{Ethics approval and consent to participate}

The study was approved by the Institutional Review Boards of Hospital Authority Kowloon West Cluster, Kowloon Central and Kowloon East Cluster and New Territories West Cluster. (REC Reference number: KW/FR -18-138(129-05); KC/KE-19-0054/ER-4; NTWC/REC/20047). Informed consent was obtained in person aided by an information sheet explaining the study, implied consent is considered given when the participants returned the completed questionnaire to the investigators in the sealed envelope provided. This method of obtaining consent was approved by the review boards. 


\section{Consent for publication}

Not applicable

\section{Availability of data and materials}

The datasets generated and analysed during the current study are available in the Mendeley Data repository (25), http://dx.doi.org/10.17632/xdcrdjs48f.2

\section{Declaration of competing interests}

The author(s) declared no potential conflicts of interest with respect to the research, authorship and/or publication of this article.

\section{Funding}

The authors received no financial support for the research, authorship and publication of this article.

\section{Authors' contributions}

Conceptualisation: WKH, WOF and WKW. Methodology: WKH, WOF, WKW, MHM, LCH and SYN. Investigation: WKH, KWY, TCF and LSK. Data Curation: WKH and WOF. Formal analysis: WKH, WOF, MY, WKW. Project administration: WKH, KWY and LSK. Visualisation: WKH and MY. Writing-original draft: WKH, MY, WOF and WKW. Writing-review \& editing: MY, WOF, WKW, KWY, TCF, LSK, MHM, LCH, SYN. Supervision: WOF, WKW, MHM, LCH, SYN. All authors have read and approved the manuscript.

\section{Acknowledgements}

The authors would like to acknowledge Dr. Yat Chun Chan for his contribution to the administration of questionnaires.

\section{References}

1. Census and Statistics Department, Hong Kong Special Administrative Region. Hong Kong Monthly Digest of Statistics (July 2018). Available from: https://www.statistics.gov.hk/pub/B10100022018MM07B0100.pdf (accessed July 16, 2018).

2. World Health Organisation (WHO). WHO Definition of Palliative Care. Available from: www.who.int/cancer/palliative/definition/en (accessed July 16, 2018).

3. Treatment and care towards the end of life: good practice in decision making. Available from: https://www.gmc-uk.org/End_of_life.pdf_32486688.pdf (accessed March 26, 2018).

4. Hospital Authority, Hong Kong Special Administrative Region. Strategic Service Framework for Palliative Care. Available from: http://www.ha.org.hk/haho/ho/ap/PCSSF_1.pdf (accessed March 16, 2018). 
5. Yim KM, Ko HF, Yang ML, Li TY, Ip S, Tsui J. A paradigm shift in the provision of improved critical care in the emergency department. Hong Kong Medical Journal 2018; 24(3); 293-297

6. Wong OF, Ko S, Cheung WH, Wong WY, Ma HM, Lit ACH. Emergency Critical Care Service in Emergency Medicine Ward: The Experience in North Lantau Hospital. Hong Kong Journal of Emergency Medicine; 2017; 24(1):25-34.

7. Todd KH. Practically speaking: Emergency medicine and the palliative care movement. Emergency Medicine Australasia 2012; 24(1): 4-6.

8. Beckstrand RL, Wood RD, Callister LC, Luthy KE, Heaston S. Emergency Nurses Suggestions for Improving End-of-Life Care Obstacles. Journal of Emergency Nursing 2012; 38(5):e7-e14.

9. Wolf LA, Delao AM, Perhats C, Clark PR, Moon MD, Baker KM, Carman MJ, Zavotsky KE, Lenehan G. Exploring the Management of Death: Emergency Nurses' Perceptions of Challenges and Facilitators in the Provision of End-of-Life Care in the Emergency Department. Journal of Emergency Nursing 2015; 41(5):e23-e33.

10. Decker K, Lee S, Morphet J. The experiences of emergency nurses in providing end-of-life care to patients in the emergency department. Australasian Emergency Nursing Journal 2015; 18(2):68-74.

11. Tse JWK, Hung MSY, Pang SMC. Emergency Nurses' Perceptions of Providing End-of-Life Care in a Hong Kong Emergency Department: A Qualitative Study. Journal of Emergency Nursing 2016; 42(3): 224-232.

12. Marck $\mathrm{CH}$, Weil J, Lane H, Weiland TJ, Philip J, Boughey M, Jelinek GA. Care of the dying cancer patient in the emergency department: findings from a National survey of Australian emergency department clinicians. Internal Medicine Journal 2014; 44(4): 362-368.

13. Shearer FM, Rogers IR, Monterosso L, Ross-Adjie G, Rogers JR. Understanding emergency department staff needs and perceptions in the provision of palliative care. Emergency Medicine Australasia 2014; 26(3): 249-255.

14. Russ A, Mountain D, Rogers IR, Shearer F, Monterosso L, Ross-Adjie G, Rogers JR. Staff perceptions of palliative care in a public Australian, metropolitan emergency department. Emergency Medicine Australasia 2015; 27(4): 287-294.

15. Elm EV, Altman DG, Egger M, Egger M, Pocock SJ, Gøtzsche PC, Vandenbroucke JP. The Strengthening the Reporting of Observational Studies in Epidemiology (STROBE) Statement: Guidelines for Reporting Observational Studies. PLoS Medicine 2007; 4(10): e296. Epub ahead of print October 2007. DOI: 10.1371/journal.pmed.0040296

16. Bennett C, Khangura S, Brehaut JC, Graham ID, Moher D, Potter BK, Grimshaw JM. Reporting Guidelines for Survey Research: An Analysis of Published Guidance and Reporting Practices. PLoS Medicine 2011; 8(8): e1001069. Epub ahead of print February 2011. DOI:

10.1371/journal.pmed.1001069.

17. Chan YC, Yang MLC, Ho HF. Characteristics and Outcomes of Patients Referred to an Emergency Department-Based End-of-Life Care Service in Hong Kong: A Retrospective Cohort Study. American 
Journal of Hospice and Palliative Medicine 2020; 104990912092614. Epub ahead of print May 2020. DOI:10.1177/1049909120926148

18. The University of Wollongong, Australia. The Palliative Care Evaluation Tool Kit: A compendium of tools to aid in the evaluation of palliative care projects. Available from:

http://ro.uow.edu.au/cgi/viewcontent.cgi?article=1004\&context=chsd (accessed March 14, 2018).

19. Rivera MR and Torres FS. Physician Attitudes on the Provision of Palliative Care in Puerto Rican Emergency Departments. Journal of Palliative Care \& Medicine 2014; 05(1): 201-205.

20. Jelinek GA, Marck CH, Weiland TJ, Philip J, Boughey M, Weil J, Lane H. Caught in the middle: tensions around the emergency department care of people with advanced cancer. Emergency Medicine Australasia 2013; 25(2): 154-160.

21. Beckstrand RL, Smith MD, Heaston S, Bond AE. Emergency nurses' perceptions of size, frequency, and magnitude of obstacles and supportive behaviors in end-of-life care. Journal of Emergency Nursing 2008; 34(4): 290-300.

22. Lamba S, Nagurka R, Zielinski A, Scott SR. Palliative Care Provision in the Emergency Department: Barriers Reported by Emergency Physicians. Journal of Palliative Medicine 2013; 16(2): 143-147.

23. Stone SC, Mohanty S, Grudzen CR, Shoenberger J, Asch S, Kubricek K, Lorenz KA. Emergency Medicine Physicians Perspectives of Providing Palliative Care in an Emergency Department. Journal of Palliative Medicine 2011; 14(2): 1333-1338.

24. Smith AK, Fisher J, Schonberg MA, Pallin DJ, Block SD, Forrow L, Phillips RS, McCarthy EP. Am I doing the right thing? Provider perspectives on improving palliative care in the emergency department. Annals of Emergency Medicine 2009; 54(1): 86-93, 93.e1.

25. Asch DA, Jedrziewski MK \& Christakis NA. Response rates to mail surveys published in medical journals. Journal of Clinical Epidemiology 1997; 50(10):1129- 1136.

26. Cummings SM, Savitz LA, Konrad TR. Reported response rates to mailed physician questionnaires. Health Services Research 2001; 35(6):1347-1355.

27. Field TS, Cadoret CA, Brown ML, Ford M, Greene SM, Hill D, Hornbrook MC, Meenan RT, White MJ, Zapka JM. Surveying physicians. Do components of the "Total Design Approach" to optimizing survey response rates apply to physicians? Medical Care 2002; 40(7):596-606.

28. Quest TE, Marco CA, Derse AR. Hospice and Palliative Medicine: New Subspecialty, New Opportunities. Annals of Emergency Medicine 2009;54(1):94-102.

29. Wong KH, Lam SKT, Kwong WY, Chan YC, Tse CFB, Yang MLC, Wong OF. Dataset for Attitude of emergency doctors in providing palliative and end-of-life care in Hong Kong and education needs: A prospective cross-sectional analysis based on self-reported surveys. Mendeley Data, v2. http://dx.doi.org/10.17632/xdcrdjs48f.2

\section{Tables}


Table 1. Characteristics of participating hospitals

\begin{tabular}{llllll} 
Hospital & $\begin{array}{l}\text { Type of } \\
\text { healthcare } \\
\text { delivered }\end{array}$ & $\begin{array}{l}\text { EoL service } \\
\text { available in } \\
\text { AED }\end{array}$ & $\begin{array}{l}\text { Number of } \\
\text { respondents vs } \\
\text { total staff }\end{array}$ & $\begin{array}{l}\text { AED attendance } \\
\text { per year (2018- } \\
\text { 2019) }\end{array}$ & $\begin{array}{l}\text { Number } \\
\text { of EMW } \\
\text { beds }\end{array}$ \\
$\begin{array}{l}\text { North } \\
\text { Lantau } \\
\text { Hospital }\end{array}$ & Secondary & Yes & $28 / 33$ & 93057 & 60 \\
$\begin{array}{l}\text { Queen } \\
\text { Elizabeth } \\
\text { Hospital }\end{array}$ & Tertiary & Yes & $34 / 44$ & 185515 & 80 \\
$\begin{array}{l}\text { Princess } \\
\text { Margaret } \\
\text { Hospital }\end{array}$ & Tertiary & No & $23 / 34$ & 123698 & 34 \\
$\begin{array}{l}\text { Tuen Mun } \\
\text { Hospital }\end{array}$ & Tertiary & No & $30 / 41$ & 173467 & 30 \\
$\begin{array}{l}\text { Pok Oi } \\
\text { Hospital }\end{array}$ & Secondary & No & $16 / 21$ & 110093 & 30 \\
$\begin{array}{l}\text { Tin Shui } \\
\text { Wai } \\
\text { Hospital }\end{array}$ & Secondary & No & $16 / 22$ & 109642 & \\
\hline
\end{tabular}


Table 2. Baseline characteristics of

respondents

Characteristics

$\begin{array}{lll}\begin{array}{l}\text { Overall } \\ (\mathrm{n}=145)\end{array} & \begin{array}{l}\text { EOL group }(\mathrm{n}= \\ 60)\end{array} & \begin{array}{l}\text { Non-EOL group } \\ (\mathrm{n}=85)\end{array} \\ \mathrm{n}(\%) & \mathrm{n}(\%) & \mathrm{n}(\%)\end{array}$

Gender (Male)

$100(69)$

$41(68.3)$

59 (69.4)

Years of experience in AED

$<5$

$50(34.5)$

$18(30)$

32 (37.6)

5-10

$31(21.4)$

$15(25)$

16 (18.8)

10-15

27 (18.6)

8 (13.3)

19 (22.4)

$15-20$

15 (10.3)

7 (11.7)

8 (9.4)

$>20$

$22(15.2)$

$12(20)$

$10(11.8)$

AED training status

Service doctor

$16(11.0)$

5 (8.3)

11 (12.9)

Basic trainee

38 (26.2)

$16(26.7)$

$22(25.9)$

Higher trainee

$29(20)$

13 (21.7)

$16(18.8)$

Specialist

$62(42.8)$

$26(43.3)$

$36(42.4)$

Training status in palliative and EOL care

Specialist training

$0(0)$

$0(0)$

$0(0)$

Short courses or other formal training

$4(2.8)$

$3(5)$

$1(1.2)$

not leading to a specialist qualification

On job training only

$56(38.6)$

$29(48.3)$

27 (31.8)

No training

$85(58.6)$

$28(46.7)$

$57(67.1)$

Self-rating of knowledge of palliative and

EOL care

No knowledge

$34(23.4)$

$15(25)$

$19(22.4)$

General knowledge only

109 (75.2)

$43(71.7)$

$66(77.6)$

Professional/ extensive knowledge

$2(1.4)$

2 (3.3)

$0(0)$

Experience of caring dying patients

$112(77.2)$

$52(86.7)$

$60(70.6)$

Confidence in caring dying patients

All of the time

$1(0.7)$

$0(0)$

$1(1.2)$ 


\begin{tabular}{llll}
\hline Most of the time & $29(20)$ & $19(31.7)$ & $10(11.8)$ \\
\hline Undecided & $38(26.2)$ & $15(25)$ & $23(27.1)$ \\
\hline Somewhat & $29(20)$ & $12(20)$ & $17(20)$ \\
\hline Not at all & $15(10.3)$ & $6(10)$ & $9(10.6)$ \\
\hline $\begin{array}{l}\text { Self-rating of support in caring dying } \\
\text { patients }\end{array}$ & & & \\
\hline Yes & $26(17.9)$ & $20(33.3)$ & $6(7.1)$ \\
\hline No & $59(40.7)$ & $24(40)$ & $35(41.2)$ \\
\hline Don't know & $27(18.6)$ & $8(13.3)$ & $19(22.4)$ \\
\hline
\end{tabular}

Remarks:

AED: Accident and Emergency

EOL: end-of-life 
Table 3. Attitude in providing EOL care

\begin{tabular}{|c|c|c|c|c|}
\hline & Statements & $\begin{array}{l}\text { EOL } \\
\text { group } \\
\text { (mean, } \\
\text { SD) }\end{array}$ & $\begin{array}{l}\text { Non-EOL } \\
\text { group } \\
\text { (mean, SD) }\end{array}$ & $\begin{array}{l}\text { P-value } \\
\text { (Mann } \\
\text { Whitney U } \\
\text { test) }\end{array}$ \\
\hline 1 & $\begin{array}{l}\text { Palliative and EOL care is an important } \\
\text { competence } \\
\text { for an emergency medicine physician. }\end{array}$ & $\begin{array}{l}3.62, \\
0.922\end{array}$ & $3.14,0.953$ & $0.004^{*}$ \\
\hline 2 & $\begin{array}{l}\text { I have a clear idea of the role of palliative } \\
\text { and EOL care in the emergency } \\
\text { department. }\end{array}$ & $\begin{array}{l}3.08 \\
0.944\end{array}$ & $2.54,0.867$ & $0.001^{*}$ \\
\hline 3 & $\begin{array}{l}\text { Emergency medicine physicians are } \\
\text { trained to save lives and not to manage } \\
\text { death. }\end{array}$ & $\begin{array}{l}2.07 \\
0.899\end{array}$ & $2.72,1.042$ & $<0.001 *$ \\
\hline 4 & $\begin{array}{l}\text { My workplace does not have protocols or } \\
\text { services } \\
\text { addressing palliative and EOL issues. }\end{array}$ & $\begin{array}{l}1.95 \\
0.910\end{array}$ & $3.46,0.946$ & $<0.001^{*}$ \\
\hline 5 & $\begin{array}{l}\text { I feel comfortable providing palliative and } \\
\text { EOL care } \\
\text { in the emergency department. }\end{array}$ & $\begin{array}{l}3.32 \\
0.911\end{array}$ & $2.35,0.882$ & $<0.001^{\star}$ \\
\hline 6 & $\begin{array}{l}\text { Palliative and EOL care should not be the } \\
\text { responsibility of the emergency physician. }\end{array}$ & $\begin{array}{l}2.07 \\
0.907\end{array}$ & $2.79,0.989$ & $<0.001^{\star}$ \\
\hline 7 & $\begin{array}{l}\text { Palliative and EOL care should have a } \\
\text { lower priority } \\
\text { in the busy emergency department. }\end{array}$ & $\begin{array}{l}2.53 \\
1.127\end{array}$ & $3.20,1.056$ & $0.001^{*}$ \\
\hline 8 & $\begin{array}{l}\text { There is lack of access to palliative and } \\
\text { EOL care } \\
\text { specialists/ teams in the emergency } \\
\text { department. }\end{array}$ & $\begin{array}{l}3.42 \\
1.013\end{array}$ & $3.91,0.718$ & $0.002^{*}$ \\
\hline 9 & $\begin{array}{l}\text { Having no access to communication with } \\
\text { palliative care } \\
\text { physician affects my ability to provide EOL } \\
\text { care } \\
\text { in the emergency department. }\end{array}$ & $\begin{array}{l}3.43 \\
0.767\end{array}$ & $3.60,0.889$ & 0.104 \\
\hline 10 & $\begin{array}{l}\text { I have difficulty discussing palliative and } \\
\text { EOL issues } \\
\text { with patients and/or their families. }\end{array}$ & $\begin{array}{l}2.87 \\
0.929\end{array}$ & $3.22,0.968$ & $0.033^{*}$ \\
\hline 11 & $\begin{array}{l}\text { I cannot identify patients who may need } \\
\text { palliative and } \\
\text { EOL care in the emergency department. }\end{array}$ & $\begin{array}{l}2.45 \\
0.891\end{array}$ & $2.78,0.931$ & $0.035^{\star}$ \\
\hline 12 & $\begin{array}{l}\text { My lack of training in palliative and EOL } \\
\text { care affects my } \\
\text { ability to provide this service. }\end{array}$ & $\begin{array}{l}3.27 \\
0.972\end{array}$ & $3.59,0.791$ & $0.046 *$ \\
\hline 13 & $\begin{array}{l}\text { Fear of lawsuits leads me away from } \\
\text { offering palliative }\end{array}$ & $\begin{array}{l}2.65 \\
0.880\end{array}$ & $3.05,0.962$ & $0.016^{*}$ \\
\hline
\end{tabular}


and EOL care to potential candidate.

14 I do not have sufficient time during my shift to provide

3.62 ,

palliative and EOL care in the emergency

1.010

$3.81,0.809 \quad 0.296$

department.

15

The emergency department is not the best place for EOL

2.93,

1.056

$3.55,0.906 \quad 0.001^{*}$ discussions

\section{Remarks}

AED: Accident and Emergency

EOL: end-of-life

SD: standard deviation

Asterisk*: $p<0.05$ 
Table 4. Obstacles (statements $4,8,9,11$ to 14 ) correlated with overall impression (statement 15)

\begin{tabular}{|c|c|c|c|}
\hline $\begin{array}{l}\text { Statements } \\
\text { number }\end{array}$ & Statement & $\begin{array}{l}\text { Correlation } \\
\text { coefficient }\end{array}$ & $\begin{array}{l}\text { P-value (Spearman rank } \\
\text { correlation) }\end{array}$ \\
\hline 4 & $\begin{array}{l}\text { "My workplace does not have protocols } \\
\text { or services } \\
\text { addressing palliative and EOL issues." }\end{array}$ & 0.219 & $0.008^{*}$ \\
\hline 8 & $\begin{array}{l}\text { "There is lack of access to palliative } \\
\text { and EOL care } \\
\text { specialists/ teams in the emergency } \\
\text { department." }\end{array}$ & 0.172 & $0.039 *$ \\
\hline 9 & $\begin{array}{l}\text { "Having no access to communication } \\
\text { with palliative care } \\
\text { physician affects my ability to provide } \\
\text { EOL care } \\
\text { in the emergency department." }\end{array}$ & 0.115 & 0.168 \\
\hline 11 & $\begin{array}{l}\text { "I cannot identify patients who may } \\
\text { need palliative and } \\
\text { EOL care in the emergency } \\
\text { department." }\end{array}$ & 0.171 & $0.040 *$ \\
\hline 12 & $\begin{array}{l}\text { "My lack of training in palliative and } \\
\text { EOL care affects my } \\
\text { ability to provide this service." }\end{array}$ & 0.043 & 0.607 \\
\hline 13 & $\begin{array}{l}\text { "Fear of lawsuits leads me away from } \\
\text { offering palliative } \\
\text { and EOL care to potential candidate." }\end{array}$ & 0.334 & $<0.001^{*}$ \\
\hline 14 & $\begin{array}{l}\text { "I do not have sufficient time during my } \\
\text { shift to provide } \\
\text { palliative and EOL care in the } \\
\text { emergency department." }\end{array}$ & 0.213 & $0.010 *$ \\
\hline
\end{tabular}

Remarks

Asterisk*: $p<$

0.05 
Table 5. Items indicated for further education needs

\begin{tabular}{|c|c|c|c|c|}
\hline Items & $\begin{array}{l}\text { Overall } \\
(n=145)\end{array}$ & $\begin{array}{l}\text { EOL group } \\
(n=60)\end{array}$ & $\begin{array}{l}\text { Non-EOL } \\
\text { group }(n=85)\end{array}$ & $\begin{array}{l}P \text { value (Chi } \\
\text { square test) }\end{array}$ \\
\hline & $\mathrm{n}(\%)$ & $n(\%)$ & $\mathrm{n}(\%)$ & \\
\hline Pain assessment and management & $\begin{array}{l}100 \\
(69.0)\end{array}$ & $40(66.7)$ & $60(70.6)$ & 0.615 \\
\hline Management of terminal delirium & $\begin{array}{l}82 \\
(56.6)\end{array}$ & $39(65)$ & $43(50.6)$ & 0.085 \\
\hline Management of dyspnea & $\begin{array}{l}95 \\
(65.5)\end{array}$ & $40(66.7)$ & $55(64.7)$ & 0.807 \\
\hline Management of death rattle & $\begin{array}{l}63 \\
(43.4)\end{array}$ & $32(53.3)$ & $31(36.5)$ & $0.044^{*}$ \\
\hline Management of feeding in EOL care & $\begin{array}{l}62 \\
(42.8)\end{array}$ & $34(56.7)$ & $28(32.9)$ & $0.004^{*}$ \\
\hline $\begin{array}{l}\text { Management of psych-social aspect } \\
\text { of EOL }\end{array}$ & $\begin{array}{l}62 \\
(42.8)\end{array}$ & $35(58.3)$ & $27(31.8)$ & $0.001 *$ \\
\hline $\begin{array}{l}\text { Management of spirituality and } \\
\text { cultural aspects in EOL }\end{array}$ & $\begin{array}{l}45 \\
(31.0)\end{array}$ & $29(48.3)$ & $16(18.8)$ & $<0.001^{\star}$ \\
\hline Bereavement management & $\begin{array}{l}78 \\
(53.8)\end{array}$ & $34(56.7)$ & $44(51.8)$ & 0.560 \\
\hline Last office and ritual arrangement & $\begin{array}{l}47 \\
(32.4)\end{array}$ & $24(40)$ & $23(27.1)$ & 0.101 \\
\hline Communication skills & $\begin{array}{l}92 \\
(63.4)\end{array}$ & $42(70)$ & $50(58.8)$ & 0.169 \\
\hline EOL care ethics & $\begin{array}{l}97 \\
(66.9)\end{array}$ & $39(65)$ & $58(68.2)$ & 0.683 \\
\hline
\end{tabular}

Remarks

EOL: end-of-life

Asterisk*: $p<0.05$

\section{Supplementary Files}

This is a list of supplementary files associated with this preprint. Click to download.

- Questionnaire7.0.pdf 